\title{
Perihilar Bile Duct Cancer pT2b TNM
}

\section{Finding v8}

National Cancer Institute

\section{Source}

National Cancer Institute. Perihilar Bile Duct Cancer pT2b TNM Finding v8. NCI

Thesaurus. Code C134728.

Perihilar bile duct cancer with tumor invading adjacent hepatic parenchyma. (from AJCC 8th Ed.) 